\title{
A comparative study of psychiatric morbidity and associated factors in carers of patients with schizophrenia and bipolar affective disorder in Nigeria \\ AF Osundina, OO Akanni, OO Ayilara, BM Mapayi, OO Aloba, AN Otakpor
}

\section{Abstract}

\section{Background}

Schizophrenia and bipolar affective disorder are two major, long-term psychiatric disorders, often associated with considerable functional impairment. Unlike in the West, where paid informal caregivers take up the role of looking after patients with chronic illnesses, the family of the mentally ill in sub-Saharan Africa are actively involved in rendering care to their psychiatrically ill relatives. The objective of this study was to study the psychiatric morbidity in carers of patients with schizophrenia and bipolar affective disorder in Nigeria.

\section{Methods}

This was a cross-sectional study conducted in a tertiary hospital in the Southwest geo-political zone of Nigeria. Carers of patients with schizophrenia and bipolar affective disorder were included in the study. Data was gathered on patient level of functioning, as well as carer burden and carer psychological morbidity.

\section{Results}

The overall prevalence rate of psychiatric morbidity among the caregivers was $28.6 \%$. There was no statistically significant difference in the sociodemographics, psychiatric morbidity, caregiver burden and patients' functioning when the two carer groups were compared. The presence of burden in caregivers and severe impairment in patients' functioning were significantly associated with psychiatric morbidity in caregivers of patients with schizophrenia, but not with caregivers of bipolar patients

\section{Conclusions}

Providing care to patients with illnesses such as schizophrenia and bipolar affective disorder is often demanding, and may be associated with significant strain, leading to psychological distress and morbidity among caregivers.

Keywords: carers, family, schizophrenia, bipolar affective disorder, Nigeria

SL J Psychiatry 2017; 8(2): 14-19

\section{Background}

The shift towards community care for patients with mental illnesses has resulted in transferring the responsibility for the day-to-day care of patients to their family members (1). The World Health Organization in 1998 estimated that between forty to ninety percent of patients with schizophrenia and other major mental illnesses live with their families (2). The situation may perhaps be worse in developing countries where relatives of patients with chronic illnesses are often involved in the day-to-day care of these persons (3). Unlike in the Western countries where paid informal caregivers take up the role of looking after patients with chronic illnesses, the family of mentally ill in sub-Saharan Africa are actively involved in rendering care to their ill relatives.
The role of these family caregivers include supervision of patient's use of medications, assistance with activities of daily living, emotional support to patients and financial support. Family member caregivers therefore have significant demands placed on their personal, financial and social resources, which may increase the risk of anxiety and depression. Studies have consistently reported significant anxiety and/or depressive symptoms among caregivers of patients with chronic mental illnesses $(4,5)$. Furthermore, these illnesses are usually associated with some degree of disability in patients, which further contributes to psychiatric morbidity among their caregivers $(5,6)$.

A study by Molyneaux et al., amongst caregivers, found that behavioural problems and limitation in patients' 
functioning were risk factors for psychiatric morbidity among caregiver relatives of patients with major psychiatric illnesses (7). In Nigeria, a similar relationship between caregiver psychiatric morbidity and patients' level of functioning has been reported. Okewole et al. reported the prevalence of psychiatric morbidity among Nigerian caregivers of children and adolescents with psychiatric disorders to be $39.4 \%$ (8). They also found that high level of subjective burden, low level of patient functioning, high degree of patient impairment, and low level of patient education was associated with psychological distress among carers.

Most studies conducted in Nigeria on caregiver burden have been among relatives of patients with schizophrenia, with a dearth of literature on relatives of patients with bipolar affective disorder (9-13).

The need to compare the impact of two major mental disorders, schizophrenia and bipolar affective disorder (BAD), on caregivers arose from research reports in the last few years, which suggests that BAD is an equally disabling illness as schizophrenia (14). It is expected that the outcome of this study will add to the existing literature on caregiver psychiatric morbidity, the relationship between psychological distress and burden of care among caregivers, and patients' level of functioning.

\section{Methods}

\section{Study design and location}

This cross-sectional study was conducted in a tertiary hospital in the Southwest geo-political zone of Nigeria. The location of this hospital makes it accessible to patients referred from hospitals within and from outside the Southwest region of the country.

\section{Participants}

Adult caregivers who have been living with and have been directly involved in caring for the adult patients with bipolar affective disorder or schizophrenia, who had been followed up at the clinic for at least one year, were considered eligible for inclusion in this study. For the purpose of this study, a caregiver was defined as the person who was most involved with the everyday care of the patient, and and who was most likely to respond to requests by the patient for assistance, including emotional or financial support. Caregivers who were not able to communicate in the English language or who had an active medical and/or psychiatric illness were excluded from the study. Caregivers with already diagnosed psychiatric illness were excluded to minimize confounding factors which could influence study results. Caregivers of consecutive out-patients attending the psychiatry clinic were recruited for this study between March 2011 and October 2012. Informed consent was obtained prior to recruitment.
The patients were diagnosed to have above diagnoses by a consultant psychiatrist using the $10^{\text {th }}$ edition of the International Classification of Diseases (ICD-10). Patients with ICD-10 diagnoses of schizophrenia or bipolar affective disorder thereafter participated in a further interview, using the Mini International Neuropsychiatry Inventory (MINI) version 5.0, for confirmation of the diagnosis (15).

Ethical approval for the study was obtained from the Ethics and Research Committee of Obafemi Awolowo University Teaching Hospitals Complex, Ile-Ife, Osun state, Nigeria.

\section{Outcomes of interest and tools used}

Socio-demographic details of the caregivers and patients, as well as information pertaining to patient's illness was gathered using a specially designed selfadministered questionnaire given to the caregiver, and from the clinical records of the patients.

Patients' functional impairment was assessed using the Social and Occupational Functioning Assessment Scale (SOFAS). This scale is derived from the Global Assessment of Functioning Scale, to assess an individual's level of social and occupational functioning not directly influenced by the overall severity of psychiatric symptoms $(16,17)$. It also considers the effects of the individual's general medical condition in the evaluation of social and occupational functioning. The SOFAS rates functioning from a range of 1 to 100 , and higher scores indicate superior functioning. Whenever information is considered to be inadequate, a score of 0 is allocated to the patient.

The General Health Questionnaire (GHQ-12) was used to detect caregiver's psychiatric morbidity. The GHQ-12 is a well recognized, validated instrument for detection of psychiatric morbidity in general medical settings and in clinical and community settings in Nigeria (19). The bimodal scoring style was used in this study.

The caregiver's burden was assessed using the Zarit Burden Interview (ZBI). This 22-item questionnaire asks caregivers to indicate how often they experienced various thoughts or feelings on a 5 point scale ranging from 0 (never) to 4 (nearly always). The testretest reliability and face validity of ZBI has been established, and the instrument is widely used in Nigeria (20).

\section{Statistical analysis}

Analysis was done using the Statistical Package for Social Sciences (SPSS) software version 17. Most variables were grouped and results were calculated as frequencies. The GHQ-12 scores were grouped into cases or non-cases using a cut-off score of 3 , and prevalence of psychiatric morbidity calculated as percentages. The 
level of burden was dichotomized into little or no burden, and mild to severe burden using a cut off of 20 on the ZBI. Functional impairment was categorised into 2 levels using the midpoint score of 50 as the cut-off; scores above 50 were categorised as mild/moderate, and scores equal or below 50 as severe. Comparison between schizophrenia and bipolar affective disorder was done using chi square. Level of statistical significance was set at $p<0.05$.

\section{Results}

The study included 200 carers of patients with schizophrenia, and 67 carers of patients with bipolar affective disorder. There was no statistically significant difference in the socio-demographics, psychiatric morbidity, caregiver burden and patients' functioning when the two carer groups were compared (Table 1).

\begin{tabular}{|c|c|c|c|c|c|}
\hline $\begin{array}{l}\text { Socio-demographic } \\
\text { characteristics }\end{array}$ & $\begin{array}{l}\text { Schizophrenia } \\
\qquad(n=200)\end{array}$ & $\begin{array}{l}\text { Bipolar affective } \\
\text { disorder }(n=67)\end{array}$ & $\chi^{2}$ & $d f$ & pvalu \\
\hline \multicolumn{3}{|l|}{ Sex } & 0.784 & 1 & 0.376 \\
\hline Male & 110 & 41 & & & \\
\hline Female & 90 & 26 & & & \\
\hline \multicolumn{3}{|l|}{ Age group } & 0.148 & 1 & 0.701 \\
\hline$<40$ & 37 & 11 & & & \\
\hline$>=40$ & 163 & 56 & & & \\
\hline \multicolumn{3}{|l|}{ Marital status } & 2.457 & 2 & 0.239 \\
\hline Single & 20 & 4 & & & \\
\hline Married & 159 & 59 & & & \\
\hline Divorced/separated/widowed & 21 & 4 & & & \\
\hline \multicolumn{3}{|l|}{ Religion } & 1.412 & 1 & 0.235 \\
\hline Christianity & 152 & 46 & & & \\
\hline Others (Islam, traditional) & 48 & 21 & & & \\
\hline \multicolumn{3}{|l|}{ Employment status } & 0.516 & 1 & 0.472 \\
\hline Employed & 166 & 53 & & & \\
\hline Unemployed & 34 & 14 & & & \\
\hline \multicolumn{3}{|l|}{ Income } & 0.211 & 1 & 0.646 \\
\hline$<\$ 100$ & 98 & 35 & & & \\
\hline$>=\$ 100$ & 102 & 32 & & & \\
\hline \multicolumn{3}{|l|}{ Relationship with patient } & 6.685 & 4 & 0.154 \\
\hline Spouse & 44 & 20 & & & \\
\hline Parent & 109 & 26 & & & \\
\hline Child & 20 & 6 & & & \\
\hline Siblings & 15 & 7 & & & \\
\hline Others & 12 & 8 & & & \\
\hline \multicolumn{3}{|l|}{$\begin{array}{l}\text { Age at onset of } \\
\text { illness of patient (years) }\end{array}$} & 3.023 & 3 & 0.388 \\
\hline$<20$ & 36 & 10 & & & \\
\hline $20-29$ & 79 & 33 & & & \\
\hline $30-39$ & 46 & 10 & & & \\
\hline$\leq 40$ & 39 & 14 & & & \\
\hline \multicolumn{3}{|l|}{ Psychiatric morbidity* } & 0.449 & 1 & 0.503 \\
\hline None & $140(70.0 \%)$ & $50(74.6 \%)$ & & & \\
\hline Case & 59 (29.5\%) & $17(25.4 \%)$ & & & \\
\hline \multicolumn{3}{|l|}{ Level of Burden } & 2.600 & 1 & 0.107 \\
\hline Little or no burden & $79 \quad(39.5 \%)$ & $34(50.7 \%)$ & & & \\
\hline Mild-Severe & $121(60.5 \%)$ & $33(49.3 \%)$ & & & \\
\hline \multicolumn{3}{|l|}{ SOFAS (of patients) } & 0.789 & 1 & 0.374 \\
\hline Mild/moderate & $113(56.5 \%)$ & $42(62.7 \%)$ & & & \\
\hline Severe & 87 (43.5\%) & $25(37.3 \%)$ & & & \\
\hline
\end{tabular}

*Missing data 


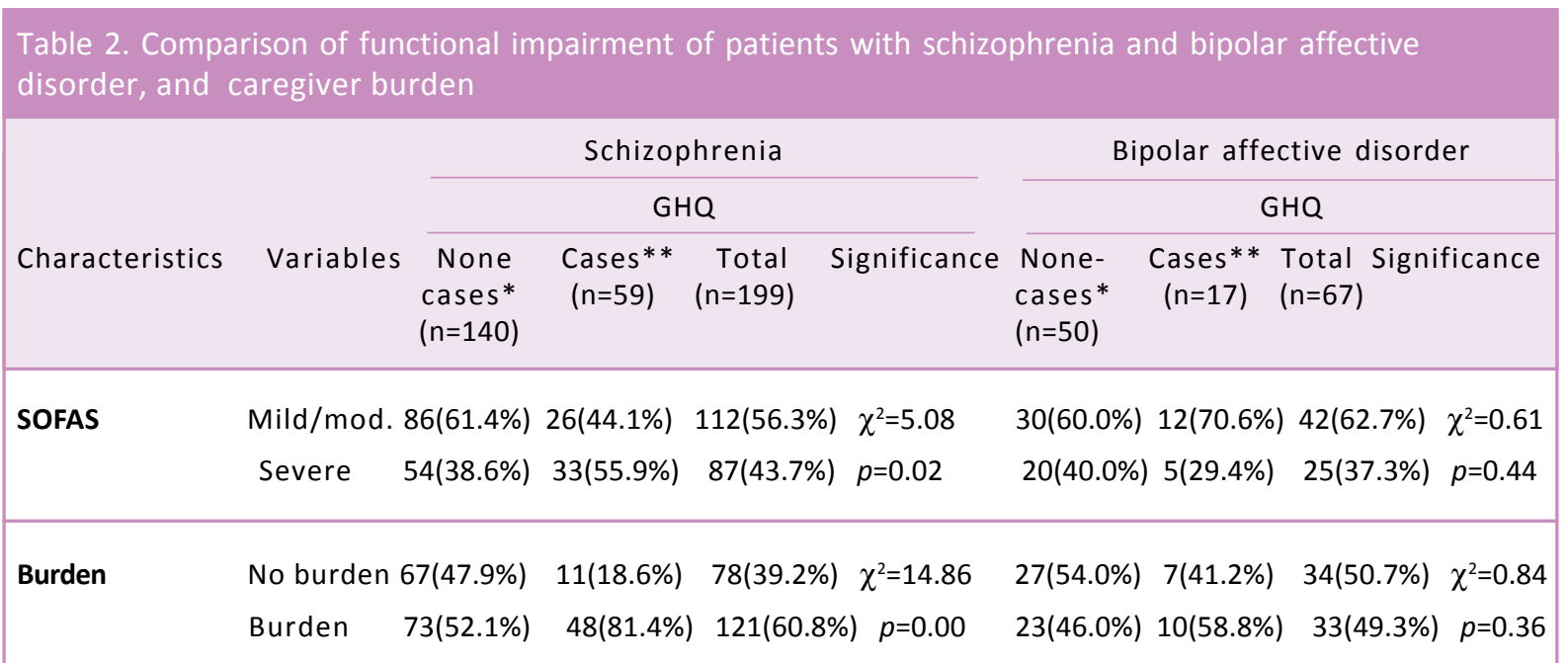

*None cases - carers with no psychiatric morbidity, ${ }^{* *}$ Cases - carers with psychiatric morbidity

The overall prevalence rate of psychiatric morbidity among the caregivers was $28.6 \%$. This study found that persons caring for patients with schizophrenia had higher psychological morbidity (29.6\%) than those caring for bipolar patients (25.4\%), although the difference between the two groups was not statistically significant $\left(\chi^{2}=0.449\right.$ $p=0.503)$. The presence of burden in caregivers $(60.5 \%$ vs. $49.3 \%$ respectively) and severe impairment in functioning of patients (43.5\% vs. $37.3 \%$ respectively) were consistently higher in schizophrenia compared to the bipolar disorder group, although again this difference was not significant.

The presence of burden in caregivers $\left(\chi^{22}=14.86, \mathrm{p}=0.00\right)$ and severe impairment in patients' functioning $\left(\chi^{2}=5.08\right.$, $p=0.02$ ) were significantly associated with psychiatric morbidity in caregivers of patients with schizophrenia, but not with caregivers of bipolar patients (Table 2).

\section{Discussion}

This study revealed a high prevalence of psychological morbidity in caregivers of patients with schizophrenia and bipolar affective disorder, which is comparable to those reported in previous studies $(21,22)$. Both these illnesses are chronic in nature and the patients usually require ongoing assistance, which may lead to caregiver frustration and burn out. Psychological distress in these caregivers may result in poor quality of care for their relatives with resultant poor prognosis in the patients' outcome. Therefore caregivers should be screened for psychiatric morbidity and treated whenever necessary.

A significant association between high burden scores and psychiatric morbidity among the caregivers of schizophrenia patients is in agreement with previous findings $(22,23)$. The association between burden and psychiatric morbidity is not surprising because of shared similarity in concept. Caregiver burden refers to the totality of the experience of caring for an ill relative, as well as the capacity to cope with and adjust to prevailing circumstances, which may include certain features also measured by psychiatric morbidity. However, this may not explain the non-association reported among caregivers of bipolar disorder patients which may need further studies to explore the disparity in findings.

The significant relationship between patient's level of functioning and psychiatric morbidity among caregivers of those with schizophrenia is similar to findings from previous studies $(8,21)$. Less severe functional impairment in patients and more periods of relatively normal functioning in patients with bipolar affective disorder when compared to schizophrenia may explain higher psychiatric morbidity among caregivers of the latter illness.

This study does not shed light on whether caregiver burden predisposes them to develop psychiatric morbidity or vice versa. Longitudinal studies in this area will help to determine the causality between burden and psychiatric morbidity. The present observation indicates that individuals who care for patients with major mental disorders, especially schizophrenia, would benefit from a well formulated mental health promotion program to take care of their own mental health needs.

\section{Limitations}

The GHQ-12 is a screening instrument for general psychiatric illness of a neurotic nature; therefore, specific diagnostic entities could not be made among caregivers. A second stage structured clinical interview would be suggested for future studies, to delineate specific mental disorders.

The study design was cross-sectional and thus no causal conclusion can be drawn from the findings. A longitudinal study would have been more appropriate. However this study, unlike most other studies in Nigeria, 
covered and compared two groups of major mental disorders. The fact that the number of carers of patients of bipolar affective disorder was considerably less than the number of schizophrenia carers, may also have influenced the findings.

\section{Conclusions}

The findings of this study suggest that informal caregivers of patients with schizophrenia and bipolar affective disorder, may develop psychiatric morbidity in the course of their caregiving role. Providing care to relatives with chronic illnesses such as schizophrenia or bipolar affective disorder is demanding, and is associated with significant strain that may lead to psychological distress and morbidity among caregivers. Hence, efforts should be made by clinicians to identify such caregivers and to provide adequate support and timely treatment interventions.

\section{Conflicts of interest}

None declared

AF Osundina, OO Akanni, OO Ayilara, Federa Neuropsychiatric Hospital, Benin-City, Edo State, Nigeria

BM Mapayi, OO Aloba, University, Ile-Ife, Osun State, Nigeria

AN Otakpor, University of Benin, Benin-City, Edo State. Nigeria

Corresponding author: AF Osundina

Email: osundinaade@yahoo.com

(iD) http://orcid.org/0000-0003-2836-7026

\section{References}

1. Stern S, Dolan M, Staples E, Szmukler G, Eisler I. Disruptive and reconstructive: Narrative insight into the experience of family member caring for a relative with diagnosis of serious mental illness. Fam Process 1999; 38 (30): 353-69.

2. World Health Organization (WHO). Nations for mental illness: Schizophrenia and public health. Geneva: WHO, 1998.

3. Wiedemann G, Hahlweg K, Hank G, Feinstein E, Muller U, Dose M. Deliverability of psychoeducational and social family management. Schizophr Bull 1994; 20(3): 547-56.

4. Cooper C, Balamurali T, Livingston G. A systematic review of the prevalence and covariates of anxiety in caregivers of people with dementia. Int Psychogeriatr 2007; 19(2): 175-95.
5. Wittmund B, Wilms H, Mory C, Angermeyer M. Depressive disorders in spouses of mentally ill patients. Soc Psychiatry Psychiatr Epidemiol 2002; 37(4): 177-82.

6. Chakrabarti S, Raj L, Kulhara P, Verma S. Comparison of the extent and patterns of family burden in affective disorders and schizophrenia. Indian J Psychiatry1995; 37(3): 105-12.

7. Molyneux C, McCarthy G, McEniff S, Cryan M, Conroy R. Prevalence and predictors of carer burden and depression in carers of patients referred to an old age psychiatric service. Int Psychogeriatr 2008; 20 (6): 1193-202.

8. Okewole A, Dada M, Ogun O, Bello-Mojeed M, Usoh T. Prevalence and correlates of psychiatric morbidity among caregivers of children and adolescents with neuropsychiatric disorders in Nigeria. Afr J Psychiatry 2011; 14(4): 306-9.

9. Martyns-Yellowe I. The burden of schizophrenia on the family. A study from Nigeria. British J Psychiatry 1992; 161(6): 779-82.

10. Ukpong D. Demographic factors and clinical correlates of burden and distress in relatives of service users experiencing schizophrenia. A study from South-Western Nigeria. Int J Ment Health Nurs 2006; 15(1): 54-9.

11. Igberase O, Morakinyo O, Lawani A, James B, Omoaregba J. Burden of care among relatives of patients with Schizophrenia in midwestern Nigeria. Int J Soc Psychiatry. 2012; 58(2): 131-7.

12. Yusuf AJ, Nuhu FT, Akinbiyi A. Caregiver burden among relatives of patients with schizophrenia in Katsina, Nigeria. South African J Psychiatry 2009; 5(2):43-7.

13. Lasebikan V, Ayinde O. Family burden in caregivers of schizophrenia patients: prevalence and sociodemographic correlates. Indian J Psychol Med 2013; 35(1): 60-6.

14. Ganguly K, Chadda R, Singh B. A study of sociocultural perspectives of caregivers in burden coping behaviours in bipolar disorder and schizophrenia cases. Int $\mathrm{J}$ Psychosocial Rehab 2009; 13(2): 93-103.

15. Sheehan D, Janavs J, Baker K, Lecruibier Y, Weiller T, Hergueta T. The MINI International neuropsychiatric interview. J Clin Psychiatry 1998; 59(S20): 22-33.

16. Endicott J, Spitzer R, Fleiss J, Cohen J. The global assessment scale. A procedure for measuring overall severity of psychiatric disturbance. Arch Gen Psychiatry 1976; 33(6): 766-71.

17. Goldman H, Skodol A, Lave T. Revising axis V for DSM IV. A review of measures of social functioning. Am J Psychiatry 1992; 149(9): 1148-56.

18. Hobbs P, Ballinger C, Smith D. Factor analysis and validation of the General Health Questionnaire in Women: a general practice survey. Br J Psychiatry 1983; 142: 257-64.

19. Gureje O, Obikoya B. The General Health Questionnaire as a screening tool in primary care setting. Social Psychiatry and Psychiatric Epidemiology 1990; 25: 276-80. 
A study of psychiatric morbidity and associated factors in carers of patients with schizophrenia in Nigeria

20. Adewuya A, Owoeye O, Erinfolami R. Psychopathology and subjective burden amongst primary caregivers of people with mental illness in South-West Nigeria. Soc Psychiatry Psychiatr Epidemiol 2010; 46(12): 1251-6.

21. Uddin M, Alam T, Ahmed H, et al. Psychiatric morbidity among caregivers of schizophrenia patients - A study in tertiary care psychiatric hospital in Dhaka. Journal of Current and Advance Medical Research 2015; 2(1): 12-17.
22. Abayomi O, Akinhanmi A, Adelufosi A. Psychiatric morbidity and subjective burden among carers of outpatients of a psychogeriatric clinic in South-Western Nigeria. J Cross Cult Gerontol 2015; 30(4): 439-50.

23. Garand L, Dew M, Eazor L, Dekosky S, Reynolds C. Caregiving burden and psychiatric morbidity in spouses of persons with mild cognitive impairment. Int J Geriatr Psychiatry 2005; 20 (6): 512-22. 